\title{
IMPLANTAÇÃO DA OUVIDORIA MUNICIPAL DE CARUARU: CIDADANIA NO EXERCÍCIO DA DEMOCRACIA
}

\author{
Luciana dos Santos Bezerra ${ }^{1}$ \\ Bruna Larissa da Silva Souza²
}

\begin{abstract}
Resumo
Partindo-se de uma análise do referencial teórico e revisão bibliográfica sobre o tema, foi analisada a implantação da Ouvidoria Municipal de Caruaru, visando conhecer o funcionamento de suas atividades desde a chegada das manifestações até a sua resposta e a constituição de uma cadeia de dados em formato de relatório eficiente na tomada de decisões e planejamento de soluções e projetos da Administração Pública. Com base na vivência diária e na pesquisa realizada para escrever este artigo, conclui-se que a Ouvidoria Municipal é instrumento de gestão participativa e resguarda a transparência e a democracia.
\end{abstract}

Palavras-chave: Ouvidoria Pública. Gestão Pública. Democracia.

1 Ouvidora-Geral do município de Caruaru-PE, advogada, graduada em Direito pela ASCES-UNITA/2008. (lucianacgmcaruaru@gmail.com)

2 Analista de Controle Interno, advogada, graduada em Direito pela ASCES-UNITA/2012. (brunacgmcaruaru@ gmail.com) 


\begin{abstract}
Starting from an analysis of the theoretical reference and bibliographical revision on the subject, it was analyzed the implantation of the Municipal Ombudsman's Office of Caruaru, aiming to know the operation of its activities from the arrival of the demonstrations to its response and the constitution of a data chain in an efficient report format in decision-making and planning of public administration solutions and projects. Based on the daily experience and the research carried out to write this article, we conclude that the Municipal Ombudsman's Office is a participatory management tool and safeguards transparency and democracy.
\end{abstract}

Keywords: Public Ombudsman. Public Administration. Democracy. 


\section{INTRODUÇÃO}

O presente artigo tem como foco o estudo da implantação da Ouvidoria Municipal de Caruaru e de como sua implantação traz um instrumento de gestão capaz de promover a mediação dos interesses da população e o exercício das funções dos agentes públicos.

O trabalho foi desenvolvido através de pesquisa bibliográfica, em livros e artigos científicos, visando à conceituação teórica sobre o tema e, ainda, traz elementos do dia a dia da Ouvidoria, pelo conhecimento pessoal das autoras e de sua vivência na área.

A Ouvidoria é o órgão de comunicação entre o cliente e a empresa, no caso da iniciativa privada, ou entre a população e a Administração Pública.

Em termos históricos, a figura do Ouvidor/Ombudsman teve seu primeiro registro na história mundial, no ano de 202 a.C., quando a China lançou a ideia de que um profissional deveria receber reclamações da população referentes às injustiças da administração imperial chinesa. Posteriormente, em 1809, a Suécia deu efetividade à função de Ouvidor/ Ombudsman, com atuação deste interlocutor entre o governo e a população, conferindo a todos os cidadãos o direito de reclamar contra atos de funcionários do rei. (SANTOS; PEREZ, 2011)

Na esfera privada a figura responsável por essa comunicação é conhecida como Ombudsman, termo de origem nórdica, mas aplicado em diversos países, incluindo o Brasil, valendo citar Odila de LARA PINTO (1998, p. 26):

- man significa, em germânico ocidental (nórdico, gótico, holandês, alemão, frisão, anglo-saxão), homem.

- bud equivalente ao alemão Bod, ao flamengo Bode, é o enviado, embaixador, delegado. - om, em alemão um e em holandês om, significa movimento ao redor de um ponto médio, em torno, de direção para. De modo que Ombudsman, literalmente, significa "homem que dá trâmite". E de acordo com COSTA (1991), ombud significa representante, delegado e man, homem. Ombudsman, portanto, seria o procurador, o defensor ou, ainda, aquele que representa. (Destaque ausente no original)

Destacamos o entendimento de que o Ouvidor é o representante do cidadão, conforme preconizado pela Associação Brasileira de Ouvidores, nos termos de seu Código de Ética e do Decálogo do Ouvidor da ABO em seu item 10: "deve o Ouvidor ser imparcial e agir como representante".

Já na esfera pública, foco do nosso estudo, temos a figura do Ouvidor, para CENTURIÃO (2003, p. 59):

Já Ouvidor é palavra mais antiga entre nós, porém com significado diverso em sua origem. O Ouvidor do Rei de tempos coloniais era representante da coroa imperial, em seu nome fiscalizando e aplicando justiça. O completo oposto do Ouvidor da máquina estatal de hoje, que é representante do cidadão perante o Estado.

Apesar de o emprego original do termo ser de sentido diametralmente oposto, entende-se porque se faz adequada sua utilização para designar o Ouvidor moderno, visto que na época ele era o contato direto com a população enquanto o rei era uma figura distante e até intangível. Tanto o Om- 
budsman quanto o Ouvidor realizam papel similar em sua essência, com fundamental importância na gerência administrativa.

Este artigo é relevante para que, através do detalhamento das características da Ouvidoria Municipal de Caruaru, se possa obter um panorama dos desafios enfrentados e do seu potencial no sentido de otimizar a participação democrática e atender ao interesse público da melhor maneira possível.

Importante contextualizar o leitor sobre o município do qual falamos nesse trabalho. Caruaru é uma cidade do agreste de Pernambuco, com aproximadamente 356.128 habitantes, segundo dados do IBGE, fundada em 18 de maio de 1857. Cidade central na economia da região, conta com a mais famosa feira livre do país e é incentivada pela sua localização geográfica, sendo cortada pelas BRs 101 e 232, além de abrigar o maior polo universitário do interior de Pernambuco. Assim, temos que a dimensão da cidade, bem como seu destaque político-social no estado de Pernambuco, demonstra sua relevância no cenário atual, de modo que um estudo da Ouvidoria Municipal de Caruaru é importante e pode servir de referência na implantação e execução de outras Ouvidorias municipais.

O município é a esfera onde o Poder Executivo pode se encontrar mais próximo do cidadão, e uma Administração Pública moderna deve atender ao princípio da eficiência, incluído no ordenamento jurídico pátrio, de forma expressa na Constituição Federal, com a promulgação da Emenda Constitucional n. ${ }^{\circ} 19$ de 04 de junho de 1998, alterando o art. 37 da Constituição. A Constituição também promove a participação direta da sociedade na gestão pública, seja através das consultas populares, dos conselhos gestores de políticas públicas, do orçamento participativo ou das próprias Ouvidorias.

Assim, para os prefeitos, as Ouvidorias municipais são um grande instrumento de análise dos clamores da população, coletando os dados mais diversos sobre serviços públicos, necessidades da cidade, infraestrutura e funcionários públicos.

\section{MARCO LEGAL E IMPLANTAÇÃO DA OUVIDORIA-GERAL DE CARUARU}

A Lei 12.527, de 18 de novembro de 2011, a afamada Lei de Acesso à Informação, foi um grande marco no sentido de promoção do interesse público e de atendimento ao princípio constitucional da publicidade (art. 37, caput, CF).

O Decreto $n^{0} 8.243$, de 23 de maio de 2014, instituiu as Ouvidorias Públicas federais na Política Nacional de Participação Social (PNPS), e no mesmo sentido a Ouvidoria-Geral da União editou a Instrução Normativa $n^{\circ} 1$, de 5 de novembro de 2014, a qual dispõe sobre as Ouvidorias Públicas do Poder Executivo Federal, e, ainda, a Portaria $n^{\circ}$ 50.253, de 15 de dezembro de 2015, que instituiu o Programa de Fortalecimento das Ouvidorias. Servindo todas essas normas como base para elaboração das legislações municipais sobre o tema, incluindo as de Caruaru.

No município de Caruaru, a Lei $n^{\circ} 5.282$, de 20 de junho de 2013 , é que dispõe sobre os procedimentos de acesso à informação, valendo destacar o art. $7^{\circ}$, que diz respeito à Ouvidoria Municipal e seu papel em relação ao SIC (Serviço de Informação ao Cidadão): 
Art. $7^{\circ}$ Os serviços de informações ao cidadão-SIC serão prestado pela Ouvidoria Municipal, que deverá:

I - atender e orientar o público quanto ao acesso a informações, encaminhando-o aos setores responsáveis, quando for o caso;

II - protocolizar os requerimentos de acesso a informações, formulados fisicamente, encaminhando-os aos setores responsáveis;

III- informar sobre a tramitação dos pedidos de acesso nas suas respectivas unidades;

IV - controlar os prazos de respostas dos pedidos de acesso, informando aos setores responsáveis a proximidade do término do prazo;

$\checkmark$ - receber as informações prestadas pelos setores responsáveis, encaminhando-as aos interessados; e

$\mathrm{VI}$ - manter histórico dos pedidos recebidos.

$\S 1^{\circ}$ Será obrigatória a existência de um SIC municipal referido no art. $7^{\circ}$ desta Lei.

$\S 2^{\circ} \mathrm{Em}$ cada órgão e entidade pública, bem como nas unidades descentralizadas, será afixado cartaz, em local com visibilidade privilegiada, com a indicação do endereço do respectivo SIC, além do endereço eletrônico onde poderá ser feito pedido de informações.

Nesse sentido, há que se falar também que a transparência atende ao artigo $5^{\circ}$, inciso XXXIII, da Constituição Federal, segundo o qual "todos têm o direito a receber dos órgãos públicos informações de seu interesse particular, ou de interesse coletivo ou geral, que serão prestadas no prazo da lei, sob pena de responsabilidade, ressalvadas aquelas cujo sigilo seja imprescindível à segurança da sociedade e do Estado".

No entanto, apesar de mencionada na Lei 5.282/2013, a Ouvidoria Municipal de Caruaru foi criada através da Lei Municipal 5.843, de março de 2017, e, segundo o art. 37 dessa lei, a Ouvidoria está vinculada à Controladoria-Geral do Município, sendo, portanto, um dos instrumentos do exercício do controle interno, aquele exercido pela própria administração, na cidade.

A Ouvidoria Municipal de Caruaru foi efetivamente implantada na data de 22 de novembro de 2017, após seis meses de elaboração e concretização de um plano de trabalho, que teve como pilares a sustentabilidade normativa, a solidez de uma equipe bem preparada e a disponibilização de material educativo à população.

A Lei no 13.460, de 26 de junho de 2017, também chamada de Lei de Proteção e Defesa dos Usuários de Serviços Públicos, é um dos principais complementos à Lei de Acesso à Informação e, em seu art. 13, traz as principais atribuições das Ouvidorias:

Art. 13. As Ouvidorias terão como atribuições precípuas, sem prejuízo de outras estabelecidas em regulamento específico:

I - promover a participação do usuário na Administração Pública, em cooperação com outras entidades de defesa do usuário;

II - acompanhar a prestação dos serviços, visando a garantir a sua efetividade;

III - propor aperfeiçoamentos na prestação dos serviços;

IV - auxiliar na prevenção e correção dos atos e procedimentos incompatíveis com os princípios estabelecidos nesta Lei;

$\mathrm{V}$ - propor a adoção de medidas para a defesa dos direitos do usuário, em observância às determinações desta Lei;

$\mathrm{VI}$ - receber, analisar e encaminhar às autoridades competentes as manifestações, acompanhando o tratamento e a efetiva conclusão das manifestações de usuário perante órgão ou entidade a que se vincula; e

VII - promover a adoção de mediação e conciliação entre o usuário e o órgão ou a entidade pública, sem prejuízo de outros órgãos competentes. 
Observa-se que o artigo art. 25 da Lei 13.460/2017 determina que esta Lei entra em vigor, a contar da sua publicação, em (inciso II) quinhentos e quarenta dias para os Municípios entre cem mil e quinhentos mil habitantes (faixa onde se enquadra a população de Caruaru). De modo que Caruaru se adiantou na implementação de uma Ouvidoria Municipal, a qual só seria obrigatória em 2019.

A Ouvidoria, a nosso ver, permite não só que o cidadão seja escutado, mas dá olhos à Administração Pública, na medida em que esta identifica o interesse público e as falhas de gestão, podendo melhor agir e planejar em cima dessas informações. Informação é poder e, no caso da Ouvidoria Municipal de Caruaru, esse poder é identificado como o poder de transformação e modernização.

Durante todo o processo da implantação, a gestão municipal, através da prefeita, esteve comprometida em oferecer a estrutura adequada para que a Ouvidoria do Município estivesse à disposição da população da melhor forma, garantindo sua ampla visibilidade e as diversas formas de acesso da população.

Atualmente, já com a Ouvidoria em pleno funcionamento, são enviados relatórios mensais de gestão elaborados pela Ouvidora-Geral, com dados quantitativos e qualitativos, à gestora máxima, além de um relatório pormenorizado trazendo demanda a demanda, onde é possível identificar os pontos de melhorias a serem implementadas. Além disso, no relatório de gestão, são propostas ações que irão solucionar falhas recorrentes que chamaram atenção pela reincidência de demandas.

Ainda sobre a relação entre a gestão máxima e a Ouvidoria, foi instituído um sólido sistema de monitoramento de gestão e, semanalmente, as ações do governo municipal são tratadas em reunião com os principais agentes políticos da administração municipal (secretários e gerentes), onde a identificação dos "gargalos" evidenciados através da Ouvidoria dá suporte para a resolução de demandas.

Outro ponto que merece destaque é a instituição do Sistema de Indicadores Municipais, onde a Ouvidoria-Geral possui seis indicadores que tratam da evolução quantitativa de recepção e resolução de demandas e que são acompanhados mensalmente pela gestora máxima do órgão.

Para além de toda a aproximação e monitoramento que a Ouvidoria-Geral de Caruaru possui com a gestão máxima do município, o órgão possui total independência e autonomia em seu funcionamento, não havendo interferência externa de nenhuma esfera da administração municipal nas atividades inerentes ao contato com o cidadão.

No art. $1^{\circ}$, da Lei $13.460 / 2017$, em seu inciso V, estão definidos os tipos de manifestações recebidas pelas Ouvidorias como "reclamações, denúncias, sugestões, elogios e demais pronunciamentos de usuários que tenham como objeto a prestação de serviços públicos e a conduta de agentes públicos na prestação e fiscalização de tais serviços".

Essas estruturas surgem como um mecanismo de diálogo permanente, de participação e controle social e, portanto, de exercício democrático. Ao mediar o acesso a bens e serviços públicos, constituem-se como um importante instrumento de gestão para a Administração Pública, que tem a oportunidade de elaborar e aperfeiçoar suas perspectivas e ações, bem como subsidiar a criação de políticas públicas. De fato, as Ouvidorias Públi- 
cas têm a potencialidade de promover a efetividade das políticas e dos serviços públicos e, em consequência, os direitos fundamentais consagrados pela Constituição Federal de 1988, sejam eles individuais, sociais, econômicos, culturais ou coletivos. (OGU, 2012c)

As manifestações mais recorrentes na Ouvidoria Municipal de Caruaru são as relativas a serviços prestados pela Secretaria da Fazenda nos quesitos de impostos, solicitações de marcação de consultas, podas de árvore, coleta de lixo, fiscalização de feira e de ambulantes, bem como do comércio em geral, e sobre o transporte público assim como assuntos relativos a educação.

Desde o momento da implantação, a Ouvidoria de Caruaru visitou todas as entidades municipais, realizando a ambientação das equipes e fortalecendo o vínculo que foi criado a partir daquele momento, o que se reflete na qualidade das respostas oferecidas aos cidadãos e no comprometimento da gestão com as atividades de todo o contexto de participação social.

O serviço da Ouvidoria Municipal de Caruaru apresenta uma estrutura física adequada ao seu funcionamento, contando com um espaço físico que compreende duas salas: a primeira onde ficam a atendente responsável pela captação das demandas por telefone, através do número gratuito 156, e presenciais, juntamente com a analista responsável pelo encaminhamento e resposta dessas demandas; já a segunda sala é utilizada pela Ouvidora e nela são desenvolvidas também as atividades de mediação. Destaca-se ainda a boa localização da Ouvidoria na cidade, instalada no centro administrativo da prefeitura, contando ainda com o auditório deste para a realização de palestras ou reuniões que demandem espaço maior e dispondo de rampa para o acesso de pessoas com deficiência, o que garante ampla e igualitária utilização por parte dos cidadãos.

Além dos membros da Ouvidoria, a equipe conta com o apoio de 23 interlocutores, que são formalmente responsáveis pelos trâmites das demandas de Ouvidoria em seu respectivo órgão. Toda a equipe encontra-se habilitada para a utilização do Sistema de Ouvidoria; para isso foram realizadas capacitações, de acordo com as funções desempenhadas por cada integrante.

A capacitação dos agentes, tanto da equipe de Ouvidoria quanto dos interlocutores, é de extrema importância. No entanto, a conscientização desses e, ainda mais, o seu dever para com o cidadão são primordiais, tanto na atenção aos prazos quanto na resposta da demanda em si. Fato é que, mesmo sendo o Ouvidor o canal de comunicação, o intermediador desse acesso, se ele não tiver uma rede de apoio nas secretarias e órgãos, seu trabalho torna-se inviável, para não dizer impossível.

Uma gestão que dá suporte à Ouvidoria é uma gestão séria e comprometida com sua função social e com o atendimento do interesse público. É evidente que o município também encontra limites, nas palavras de PEREIRA: "Existe governança em um Estado quando seu governo tem as condições financeiras e administrativas para transformar em realidade as decisões que toma" (1997, p. 40). Mas ter a representação de um órgão investido de autonomia como representante do povo perante a Administração Pública faz imensa diferença.

Nas palavras de ALCANTARA; CARDOSO; NETO (2012, p. 30):

As Ouvidorias Públicas em Estados de redemocratização recente desempenham duplo papel: o de servir de meio de participação direta, permitindo o controle social da res publica, e o de auxiliar a renovação da sociedade civil, a partir da reconstrução da confiança e do respeito, o que depende da autonomia e da eficiência das Ouvidorias Públicas. 
Assim, cabe à Ouvidoria um papel pedagógico também, pelo qual se incute na população a cultura do acompanhamento dos atos praticados. E, sendo detentor dessas informações, o cidadão desperta para o seu poder perante a Administração Pública e os órgãos de controle externo, podendo mesmo exercer ativamente seus direitos constitucionais através de manifestações populares ou ajuizamento de ações populares.

Dessa forma, a instituição de relacionamentos sólidos e de confiança mútua do Ouvidor para com o interlocutor é uma das prioridades da Ouvidoria, já que de nada adianta o melhor sistema de captação de manifestações ou o melhor atendimento na sede da Ouvidoria se o cidadão não receber a resposta que procura. Tal resposta, na maioria dos casos, depende de uma resposta de um órgão da prefeitura e não diretamente da Ouvidoria, de modo que passa por um interlocutor, daí a extrema importância da sua nomeação, bem como da sua presteza no exercício da função.

Destaca-se aqui, no mesmo sentido, o perfil almejado pela Ouvidoria para esses interlocutores, que são pessoas identificadas em cada entidade administrativa por ter sensibilidade à resolução dos problemas e gargalos enfrentados pelo seu órgão correlato, bem como proatividade, para que o trâmite da demanda seja ágil, além de amplo acesso às informações internas. Ainda, vale ressaltar a idoneidade, a conduta ética e o compromisso com o bom funcionalismo público.

A partir desse bom relacionamento, e do incansável trabalho de divulgação/educação, o fluxo das demandas tende a aumentar. Não se deve confundir esse aumento com o aumento do nível de insatisfação da população, pelo contrário, demandas sempre existirão, e o número maior delas demonstra apenas o aumento do nível de confiança da população para com a Ouvidoria. Um cidadão descrente não reclama perante o governo, pois acredita que ele não lhe dá ouvidos ou importância.

E é no contexto da comunicação integrada que a Ouvidoria precisa ser entendida e exercida, pois o trabalho que ela faz é, fundamentalmente, proporcionar que flua o processo da comunicação no âmbito interno das organizações e dessas com o seu público. (IASBECK, 2012)

Estabelecida a Ouvidoria, observa-se que captar a demanda não é seu único papel, é somente o primeiro passo. O Ouvidor precisa possuir competência gerencial de análise crítica, para com ela gerar os relatórios gerenciais necessários e as propostas a serem apontadas para a gestão, como forma de fortalecer o serviço público oferecido e garantir a eficácia e efetividade da administração enquanto garantidora de direitos.

Um grande obstáculo para a implantação da Ouvidoria é a falta de conhecimento da população sobre sua existência e sua função. O primeiro passo dado no sentido de vencer esse empecilho no município foi, num primeiro momento, a capacitação dos interlocutores para orientar a população no sentido de acesso ao canal correto, além da visibilidade do canal do sistema de Ouvidoria em formato de banner na página oficial da prefeitura.

Porém a ação que vem se destacando e fomentando a cultura de participação social na sociedade caruaruense é o trabalho de divulgação e educação "corpo a corpo" efetuado nas mais diversas ações da prefeitura e perante os órgãos que contemplam a sociedade civil organizada, como associações e conselhos. Existe uma cartilha desenvolvida especificamente para informar ao cidadão qual o seu papel como possuidor de direitos perante a Administração Pública, indicando a 
Ouvidoria como o canal de acesso ao município. O referido material tem cunho explicativo e leva ao cidadão, minuciosamente, todo o funcionamento da Ouvidoria para que ele se sinta acolhido e queira aproximar-se da entidade que é tida como a sua "casa".

A Ouvidoria Municipal de Caruaru esteve presente nas entregas de novas e requalificadas creches e escolas municipais, inclusive da zona rural, de modo que mesmo a população mais afastada do centro da cidade está sendo conscientizada da existência e do papel da Ouvidoria. Uma emissora local, a TV Jornal, esteve presente, com a Ouvidoria Itinerante, todas as sextas-feiras de março e abril, em diversos bairros da cidade: Centenário, São Francisco, Salgado, Boa Vista I e II, Vassoural e Vila Kennedy. Está sendo implementado, ainda, um trabalho com os feirantes da Feira da Sulanca, que acontece nas segundas-feiras e é o mais importante ícone da economia municipal, e com os fornecedores de alimentos da Central de Abastecimento de Caruaru (CEACA). Sendo Caruaru um polo turístico, com o título de Capital do Forró e a realização da maior e melhor Festa de São João do mundo, outro grande exemplo de aproximação com a sociedade ocorrerá com a captação de demandas e o trabalho de divulgação pela Ouvidoria durante todos os dias de evento no principal polo de atrações da cidade, o Pátio de Eventos Luiz Gonzaga. Percebe-se também que o trabalho de divulgação e orientação sobre o papel da Ouvidoria precisa ser contínuo para que possa ser eficaz.

A Ouvidoria Municipal de Caruaru, com o objetivo de máxima eficiência na prestação da informação, realiza articulações com gestores, técnicos e interlocutores das secretarias e autarquias municipais, bem como, em casos de reiteradas demandas sobre uma mesma temática, orienta e apoia esses órgãos, quer através de suporte e embasamento técnico ou algum plano de tratamento dos casos concretos e, mesmo, com as mediações de conflitos.

Outro ponto de destaque a ser trabalhado com o cidadão é em relação às demandas anônimas. Percebe-se que a grande maioria dos cidadãos não quer se identificar ao fazer uma demanda, por mais simples que ela seja. Nesse sentido, há que se demonstrar a idoneidade do órgão, bem como desmistificar a questão de represálias, garantindo, por exemplo, a identificação com restrição, onde somente o Ouvidor terá acesso ao nome do cidadão, já que quando a demanda é feita anonimamente a efetividade da percepção do cidadão sobre ela torna-se praticamente inexistente, pois ele não receberá uma resposta oficial, vez que não ofereceu meios para tanto.

Assim, nos trabalhos educativos, de divulgação e panfletagem realizados pela Ouvidoria caruaruense, procura-se informar as pessoas sobre a preservação da identidade em restrição e que, assim, somente ela receberá uma resposta formal por e-mail. Ressaltando que nos casos de manifestações anônimas recebidas por telefone também existe essa orientação.

As manifestações anônimas são encaminhadas normalmente para os interlocutores responsáveis com a indicação de demandante "não identificado", mesma denominação adotada quando há a restrição de identificação, assim o interlocutor e a secretaria ou entidade responsável não sabem se a manifestação foi anônima ou de identificação com restrição, o que os incentiva a responder. A resposta é registrada no sistema e os prazos são os mesmos adotados para a manifestação com identificação, bem como a cobrança pela resposta do órgão responsável. O cidadão pode, então, ter a resposta no contexto de sua reclamação, como, por exemplo, de caso real do conserto de um ar-condicionado no atendimento da sede administrativa. Caso não perceba essa mudança, 
verificamos que o cidadão volta a fazer manifestação anônima, pois muitas vezes são idênticas em detalhes específicos.

Todas as manifestações geram ainda os mencionados dados para relatórios qualitativos e quantitativos e, desse modo, refletem-se em políticas públicas, provocando muitas vezes iniciativas da prefeitura elaboradas com base no respaldo do cidadão. Assim, servindo de termômetro dos anseios populares e dando voz ao cidadão, a Ouvidoria exerce um importante papel democrático no município de Caruaru.

\section{CONSIDERAÇÕES FINAIS}

A Ouvidoria de Caruaru procura incutir a ideia de que a população tem, portanto, não só o direito de contar com esse canal de comunicação, como o dever cidadão de se manifestar e trazer essa informação ao conhecimento da gestão.

O trabalho realizado nos trouxe muita alegria, por entendermos que a ferramenta de Ouvidoria traz grande, e importante, contribuição para a garantia da Democracia, bem como para o fortalecimento da Gestão Pública, uma vez que, sendo implementada de forma estruturada, trará resultados rápidos e satisfatórios na melhoria da qualidade dos serviços públicos.

Escutar a população é um grande passo na transformação do serviço público, pois o gestor, assim como o administrador de uma empresa, traçando um paralelo, não está na linha de frente do atendimento ao público, não está naquela escola onde a demanda de vagas é maior que a ofertada e não saberá desses fatos, a menos que eles lhes sejam informados. Destaca-se aqui a visão que têm as autoras deste artigo, na qualidade de membros da Ouvidoria Municipal de Caruaru, de que ela possui imensa importância estratégica para a gestão do município.

Esperamos num momento futuro dar continuidade ao presente estudo apresentando um trabalho estatístico de análise das manifestações recebidas, bem como dos resultados aferidos pelos trabalhos da Ouvidoria Municipal de Caruaru a fim de demonstrar o efetivo papel desempenhado por ela desde sua implantação.

Por último, reafirmamos a relevância científica do presente estudo, que traça um importante relato da implantação e da vivência de uma Ouvidoria municipal, observando que, concretamente, a literatura sobre essas Ouvidorias específicas ainda é escassa no país.

\section{REFERÊNCIAS}

ALCANTARA, E. L. C; CARDOSO, A. S. R; NETO, F. C. L. Ouvidoria Pública e governança democrática. In: III Reunião Geral das Ouvidorias Públicas OGU, Brasília, 2013.

CARDOSO, A. S. R. Ouvidoria x Mediação: Reflexões sobre um conflito, jul. 2006. Disponível em: http://desafios. ipea.gov. br/Ouvidoria/images/ stories/pdf/artigo003.pdf. Acesso em: 10 maio 2018.

CENTURIÃO, Alberto. Ombudsman: a face da empresa cidadã. São Paulo: Educador, 2003.

IASBECK, Luiz Carlos Assis. Ouvidoria: mídia organizacional. Porto Alegre: Sulina, 2012. 
LYRA, Rubens. Ouvidor: o defensor dos direitos na Administração Pública brasileira. In: LYRA, RUBENS PINTO. Autônomas x Obedientes. A Ouvidoria Pública em debate. João Pessoa: UFPB, 2004.

OGU - OUVIDORIA-GERAL DA UNIÃO. Orientações para o atendimento ao cidadão nas Ouvidorias Públicas: rumo ao sistema participativo. Coleção Ouvidoria-Geral da União, v. 3. Brasília-DF. 2012c. Disponível em: <http://www.cgu. gov.br/Publicacoes/Ouvidoria/arquivos/ogu-atendimento-cidadao.pdf> Acesso em: 20 maio 2018.

PINTO, Odila de Lara. Ombudsman nos bancos: agente de mudanças nas instituições bancárias brasileiras. São Paulo: Musa, 1998.

SALES; L. M. M. Ouvidoria e mediação: instrumentos de acesso à cidadania. Pensar, Fortaleza, v. 11, p. 154-167, 2006.

SANTOS, Regina Célia Xavier; PEREZ, Tiago de Lima. Ouvidoria Pública: canal de comunicação entre o cidadão e a esfera pública: estudo de caso da Ouvidoria do sistema penitenciário nacional. Disponível em: http://hdl.handle. net/123456789/1169>. Acesso em: 24 maio 2018.

TEIXEIRA, E. Sociedade Civil e participação cidadã no poder local. Salvador: UFBA, 2000. 